\title{
AVALIAÇÃO DE PROPRIEDADES MECÂNICAS EM MATRIZ CIMENTÍCIA COM AGREGAÇÃo DE RESÍDUOS DA PRODUÇÃO DE BIODIESEL AO CIMENTO PORTLAND
}

\author{
Camila Stockey Erhardt ${ }^{1}$ \\ Júlia Amanda Becker ${ }^{2}$ \\ Cláudia Mendes Mallmann ${ }^{3}$ \\ Rodolfo Barbosa de Oliveira ${ }^{4}$ \\ Adriane Lawisch Rodríguez.
}

\begin{abstract}
RESUMO
Constante é a busca por materiais ecoeficientes aproveitando-se do potencial dos co-produtos e resíduos do biodiesel. Por meio de uma produção viável, este trabalho teve por objetivo a agregação das partes aéreas do girassol ao cimento Portland CP IV formando um compósito. Realizado em três etapas que foram: caracterização de resíduos, processamento de corpos de prova e ensaios. Fabricaram-se corpos de prova como matriz (CM) e corpos de prova com substituição de $10 \%$ de massa de agregado por resíduo de girassol (CG). Na pesquisa foram realizados ensaios de granulometria com o resíduo, de resistência à compressão (NBR 7215), de finura do cimento Portland (NBR 11579) e de tempo de pega (NM 65). Os resultados obtidos permitiram concluir que o compósito $\mathrm{CG}$ está dentro dos parâmetros exigidos na NBR 5736 de eficiência do CP IV, somente não alcançando a resistência à compressão desejada de $30 \mathrm{MPa}$.
\end{abstract}

Palavras-chave: Cimento Portland. Girassol. Compósito.

\begin{abstract}
Searching for ecofriendly materials by exploiting the potential of co-products and waste from biodiesel has been constant. The goal of the present work was to aggregate the sunflower aerial parts into the Portland CP IV cement forming a composite through a viable production. The three steps performed were: waste characterization, specimens processing and essays. Specimens were manufactured as matrix (CM) and specimens made of $10 \%$ of sunflower waste (CG). It was accomplished granulometry, from strenght to compression (NBR 7215) of the waste material, fineness of the Portland cement (NBR 11579) and cement setting time (NM 65). The results showed that the composite CG is in accordance with the parameters required by NBR 5736 of CP IV efficiency however the parameter resistence to the desired compression of $30 \mathrm{MPa}$ was not reached.
\end{abstract}

Keywords: Portland Cement. Sunflower. Composite

\footnotetext{
1 Acadêmica do Curso de Engenharia Civil da Universidade de Santa Cruz do Sul - UNISC. <camilaserh@hotmail.com>

2 Acadêmica do Curso de Engenharia Civil da Universidade de Santa Cruz do Sul - UNISC. <juliaamanda@gmail.com>

3 Professora do Departamento de Química e Física da Universidade de Santa Cruz do Sul - UNISC. <mclaudia@unisc.br>

4 Arquiteto e Urbanista. <arquitetorodooliveira@gmail.com>

5 Professora do Departamento de Engenharia, Arquitetura e Ciências Agrárias da Universidade de Santa Cruz do Sul - UNISC. <adriane@unisc.br>
} 


\section{INTRODUÇÃO}

A ecologia industrial oferece o conceito da circulação de matéria-prima entre unidades produtivas, na qual o que é considerado resíduo em um sistema industrial é usado em outro sistema como insumo (TEIXEIRA, 2005). Isto ocorre na produção do biodiesel, em que são gerados resíduos e co-produtos que devem ser aproveitados, de forma que toda a cadeia de produção do biodiesel seja sustentável e economicamente viável (MOTTA, 2011).

Uma das alternativas para a utilização destes resíduos está na incorporação em matriz cimentícia obtendo-se um compósito com propriedades únicas devido à combinação carga/matriz. Estes são compósitos de biomassa vegetal, que podem ser utilizados para as mais diversas finalidades em vista de suas características especiais, tais como baixa massa específica, isolamento térmico, resistência ao fogo, impermeabilidade e resistência mecânica que, embora não seja tão alta quanto à do concreto, não chega a ser desprezível (CAMARINI, 2005).

Para a comprovação do potencial destes compósitos são analisados os parâmetros incluídos na NBR 5736 sobre o Cimento Portland IV (CP-IV) que é um aglomerante hidráulico com adição de materiais pozolânicos, e o mais utilizado nas construções da região onde a pesquisa foi realizada.

\section{METODOLOGIA}

O presente trabalho realizou-se em três etapas, conforme o fluxograma da Figura 1, que especifica os processos realizados em cada etapa quanto à caracterização dos resíduos, processamento dos corpos de prova e ensaios.

\section{Figura 1 - Fluxogramas das etapas}

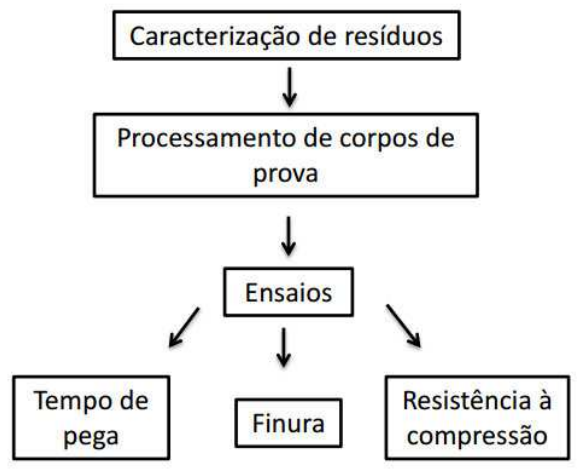




\subsection{Caracterização dos resíduos}

Primeiramente, foi realizado o recebimento de resíduos in natura no laboratório, provenientes de estágios diferentes do processo de obtenção do biodiesel na UNISC e também da colheita contidos na Figura 2, como o caule, as folhas e o capítulo do girassol, denominadas partes aéreas do girassol.

Figura 2 - Partes aéreas do girassol (capítulo, caule e folhas)
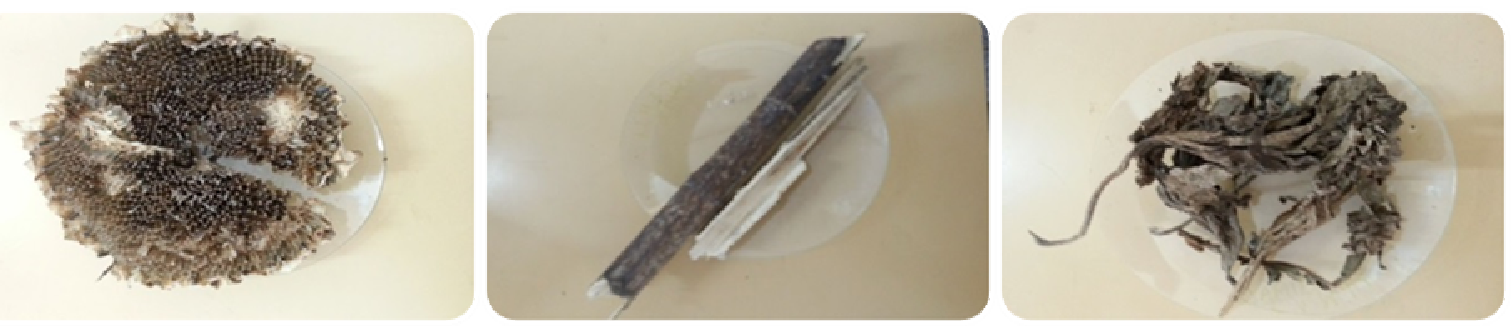

Os resíduos passaram pelo processo de maceração em moinhos de facas para a diminuição de suas dimensões. Posteriormente os resíduos foram encaminhados para o processo de secagem, no qual permaneciam por 8 horas a $50^{\circ} \mathrm{C}$ dentro da estufa para a desumidificação do material.

$\mathrm{Na}$ caracterização de sua granulometria, realizou-se o ensaio de peneiramento segundo a NBR NM-ISSO 2395. Foi realizado peneiramento mecânico com um jogo de peneiras mostrado na Figura 3, com velocidade de peneiramento 4 rpm por 10 minutos.

\section{Figura 3 - Resíduos após peneiração}

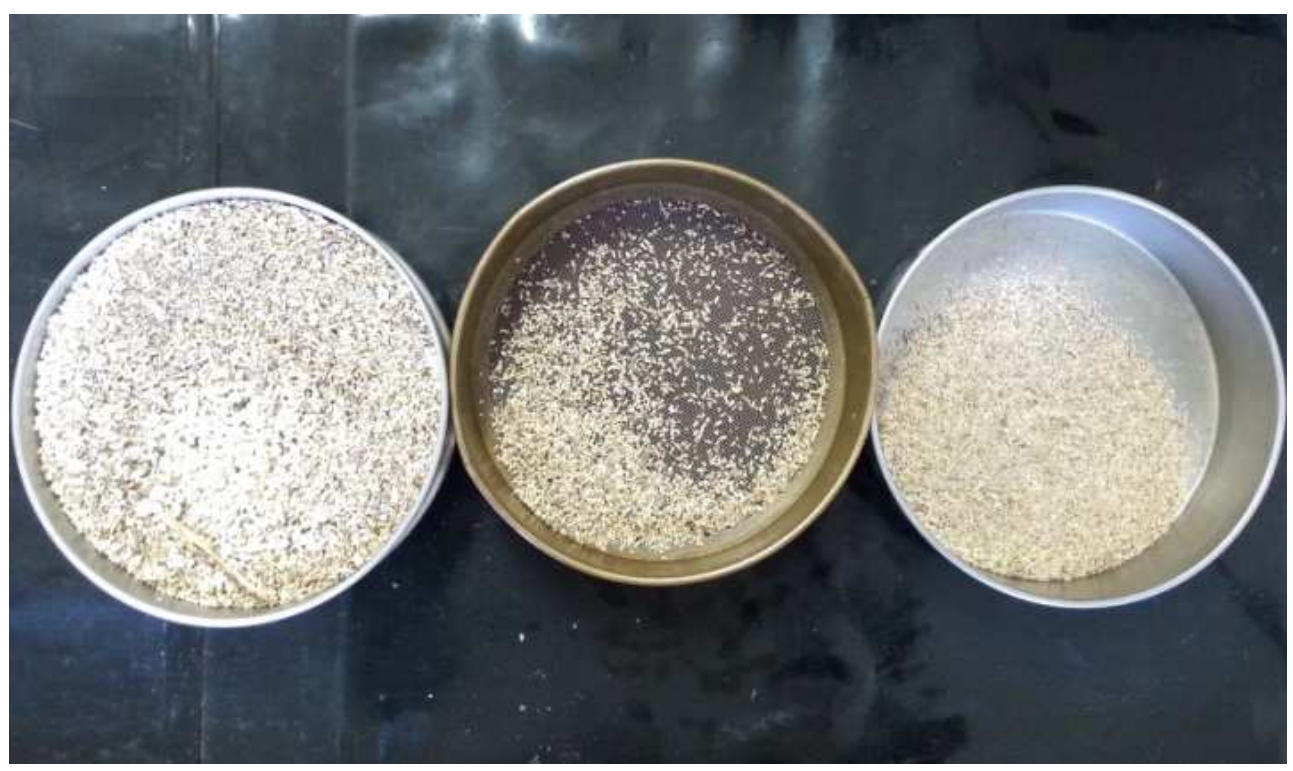


Para a utilização dos resíduos em substituição ao agregado (areia), estabeleceu-se uma granulometria igualitária para os dois materiais em análise. Para o ensaio de determinação de resistência à compressão e tempo de pega, os resíduos utilizados possuíam dimensões menores a $2 \mathrm{~mm}$.

\subsection{Processamento dos corpos de prova}

Utilizou-se o cimento Portland CP IV como aglomerante, que é um cimento constituído por materiais pozolânicos no qual apresenta diferentes propriedades conforme sua dosagem e utilização.

Para a mistura com um traço de 1:3, fez-se a pesagem dos materiais em uma balança de precisão 0,1 g. A massa foi fabricada, conforme NBR 7215, em misturador mecânico, utilizando-se cimento CP-IV, água, e a mistura de quatro areias $\left(\mathrm{n}^{\circ} 15, \mathrm{n}^{\circ} 30, \mathrm{n}^{\circ} 50\right.$ e $\left.\mathrm{n}^{\circ} 100\right)$.

Os corpos de prova foram conformados em moldes de metal não corrosível, cilíndricos com diâmetro de $50 \mathrm{~mm}$ e altura de $100 \mathrm{~mm}$. Com auxilio de uma espátula, a massa foi depositada em 4 camadas dentro do molde, conforme a Figura 4, cada camada recebendo 30 golpes com soquete de material não corrosível.

\section{Figura 4 - Moldagem dos corpos de prova}

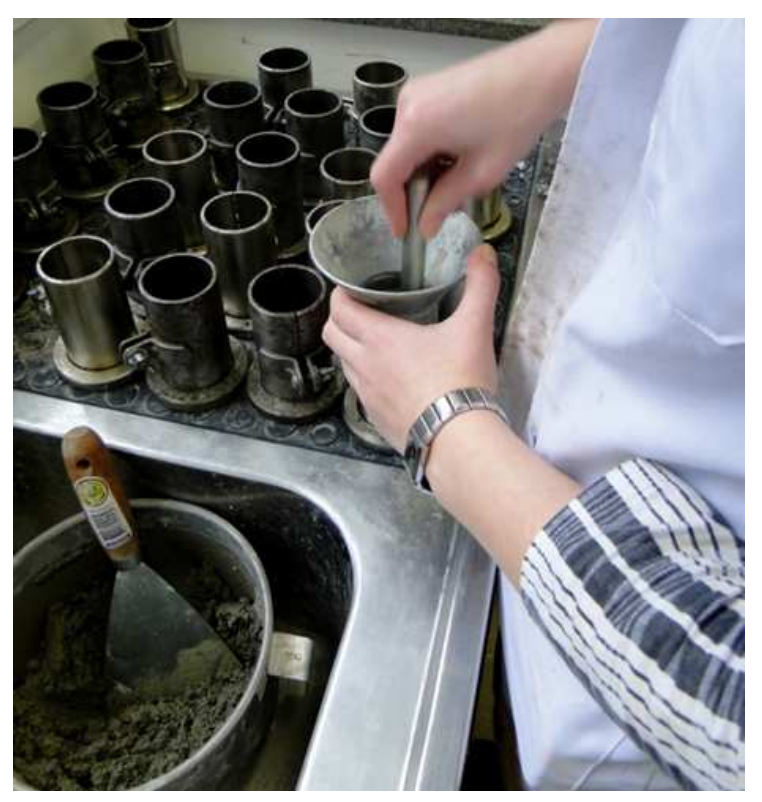

Processaram-se corpos de prova contendo somente cimento que constituíam a matriz (CM) e corpos de prova com substituição de $10 \%$ da massa de agregado por resíduos de girassol (CG) para comparação de eficiência quanto a matriz e compósito. 
Ocorreram alterações quanto à cura dos corpos de prova $\mathrm{CG}$, nos quais foi adicionada uma quantidade maior de água na mistura para que a pasta ficasse com a consistência correta e similar à matriz CM, já que os resíduos incorporavam mais água.

Os corpos de prova CM foram submetidos à cura inicial ao ar por 24 horas e, posteriormente, foi realizada a cura final em água, na qual foram retirados de dentro dos moldes, imersos e separados entre si no tanque de água.

Já com os corpos de provas CG realizou-se somente a cura a seco, retirando-se os corpos de prova dos moldes quando chegassem à idade de cura para o ensaio.

\subsection{Ensaios}

Para a constatação das propriedades do cimento e comparação entre matriz e compósito, realizou-se o ensaio de finura do cimento, o tempo de pega e a resistência à compressão com os corpos de prova.

Seguindo a norma NBR 11579 MB-3432, realizou-se a determinação da finura por

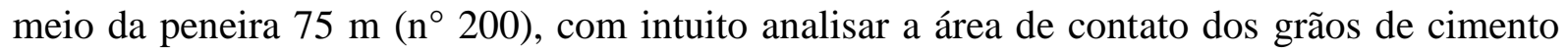
com a água da mistura.

Colocou-se a amostra de cimento utilizada para o ensaio em uma peneira de $n^{\circ} 200$, agitando-se manualmente por 3 minutos, conforme Figura 5. Após, foi pesada somente a massa que passava pela peneira, depositada no fundo. O ensaio foi realizado em duplicata.

\section{Figura 5 - Ensaio de finura do cimento}

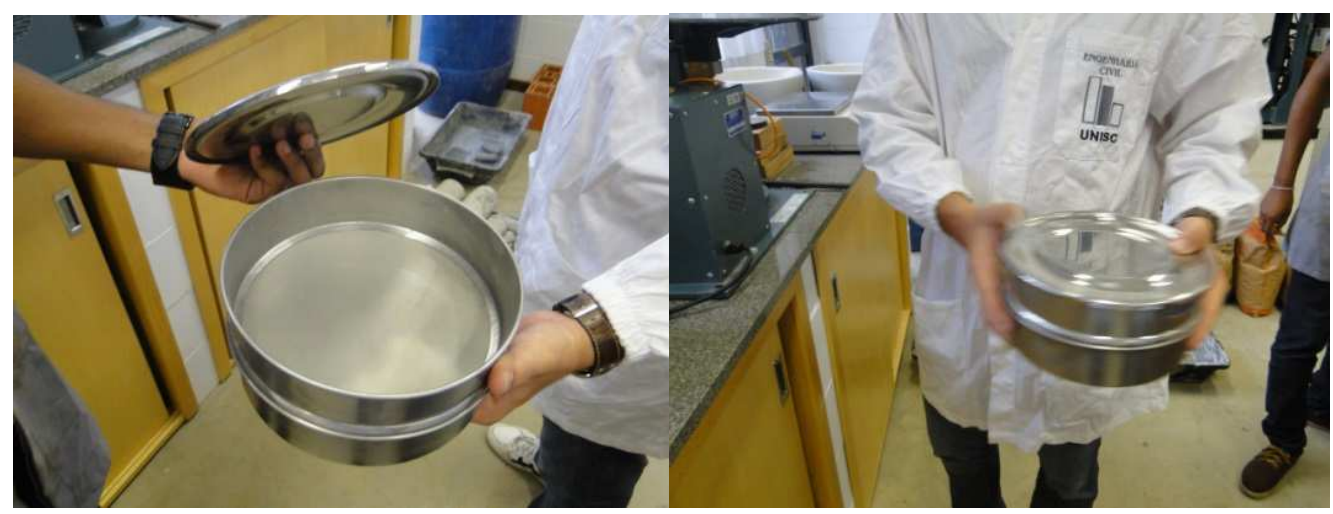

Pela NM 65:96, realizou-se a determinação do tempo de pega do cimento Portland, determinando os intervalos de fim e início de pega, para a análise de seu tempo de cura. No aparelho Vicat moldou-se a pasta de consistência normal, conforme a NM 43, no molde do aparelho. A agulha foi posicionada sobre a pasta até que permanecesse em contato e assim 
fosse solta até penetrar na pasta, como mostra a Figura 6. Foram feitas leituras de trinta em trinta minutos. Após marcar valor diferente de zero foram feitas leituras de quinze em quinze minutos até que a agulha não penetrasse mais na amostra.

\section{Figura 6 - Ensaio de tempo de pega}

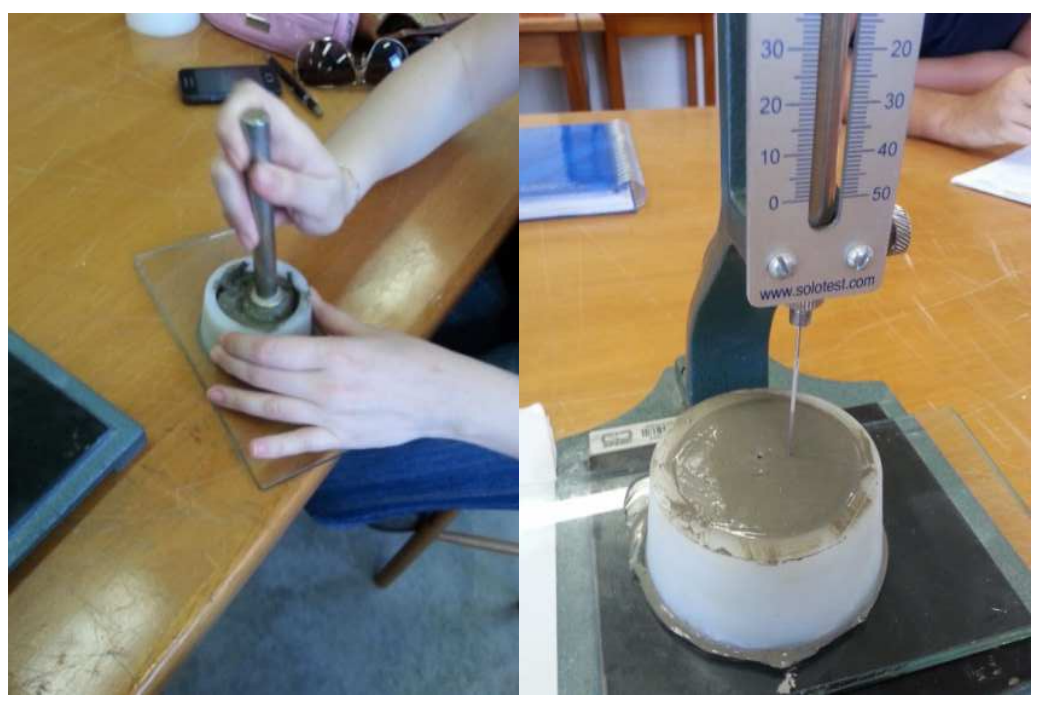

Para a determinação da resistência à compressão, de acordo com a NBR 7215, foram elaborados quatro corpos de prova por idade de cura (3, 7 e 28 dias). Realizou-se a determinação da resistência na máquina universal de ensaios, conforme Figura 7, que fazia o rompimento dos corpos de prova chegando à carga de ruptura.

\section{Figura 7 - Ensaio de resistência à compressão}

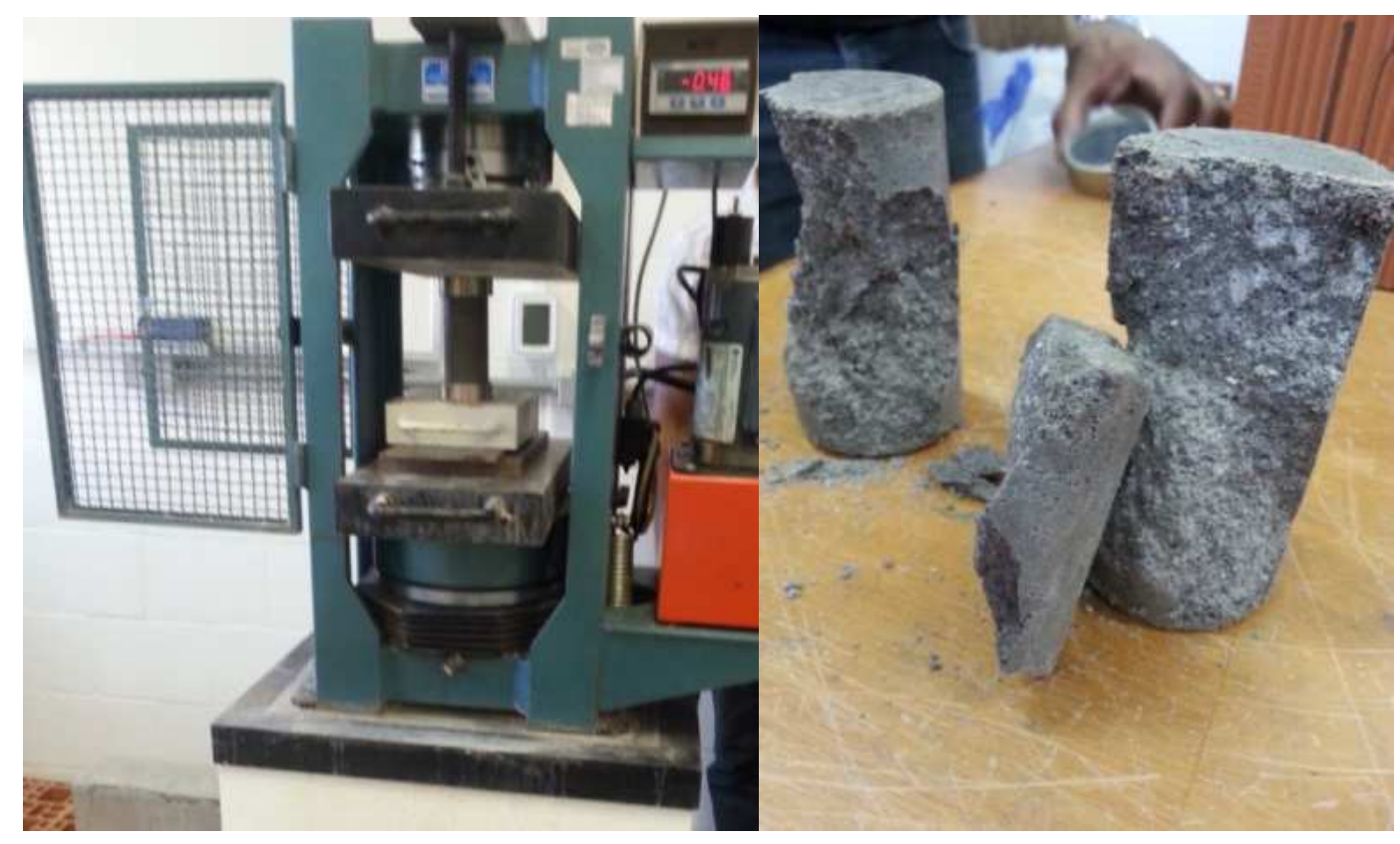




\section{RESULTADOS E DISCUSSÃO}

O ensaio granulométrico foi realizado com as partes aéreas do girassol, chegando aos resultados abaixo na Figura 8. A torta de girassol foi utilizada no processamento dos corpos de prova de matriz cimentícia. Devido ao teor residual existente de glicerol encontrado no resíduo, os corpos de prova formados não obtinham o formato necessário para a realização dos ensaios.

Obteve-se a curva granulométrica, na qual passaram $96 \%$ da massa de resíduo ensaiado na peneira de $4,00 \mathrm{~mm}, 40 \%$ na peneira de $2,00 \mathrm{~mm}$ e $12 \%$ na peneira de $1,00 \mathrm{~mm}$.

\section{Figura 8 - Gráfico de curva granulométrica}

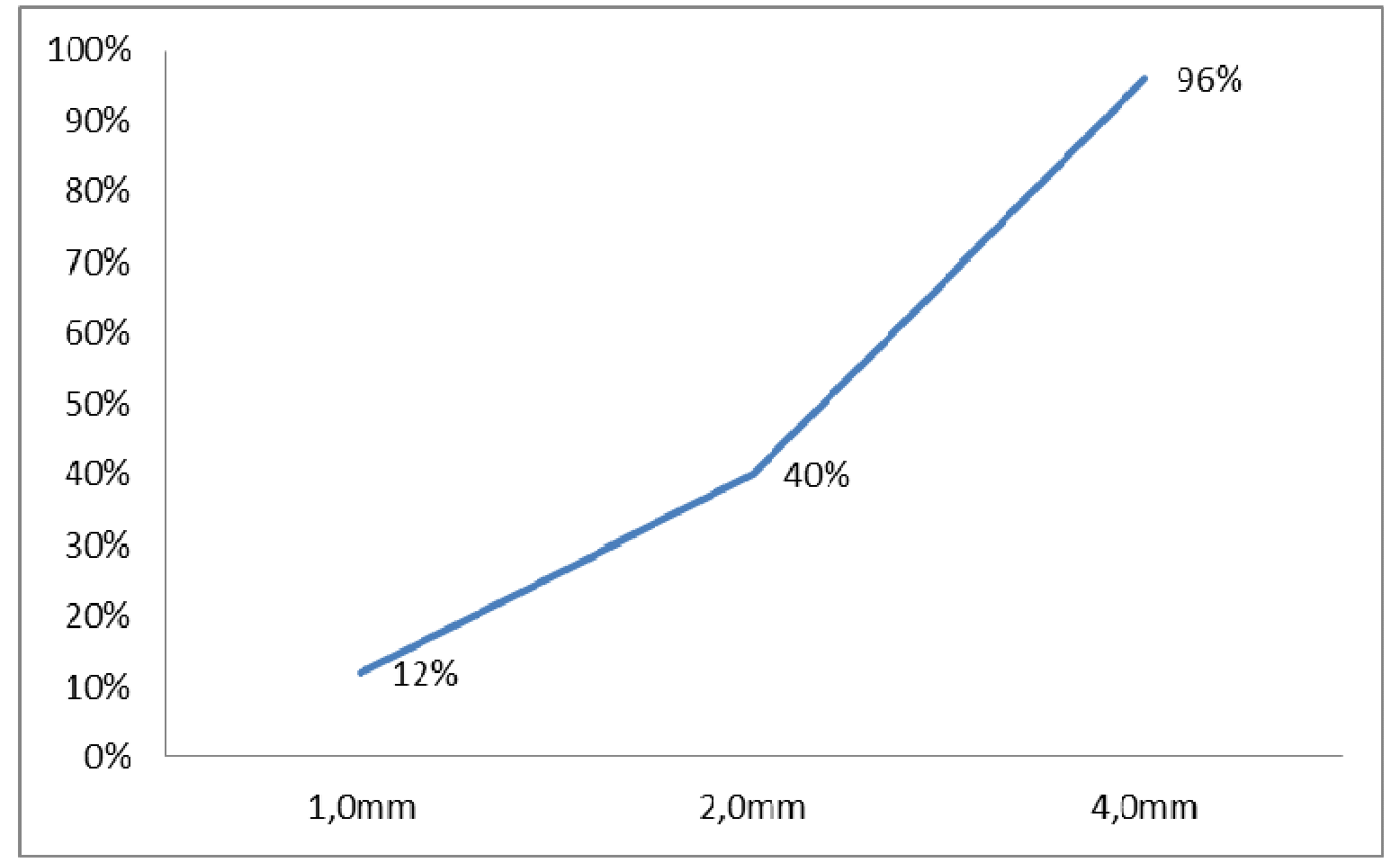

No ensaio de finura do cimento da amostra de $50 \mathrm{~g}$, somente $4 \mathrm{~g}$ (equivalente a $8 \%$ do material do ensaio) ficaram retidas nas malhas da tela, sendo possível retirá-las para pesagem. 
$\mathrm{Na}$ Tabela 1 constam os resultados obtidos pelo ensaio de tempo de pega. O tempo de início de pega de CM teve duração de 3 horas. Já o tempo de fim de pega teve duração de 4 horas e 15 minutos, quando a agulha Vicat permaneceu sob o corpo de prova. No ensaio com CG, o tempo de início de pega teve duração de 2 horas e 30 minutos, e o tempo de pega ocorreu de 5 horas e 15 minutos.

\section{Tabela 1 - Determinação do temo de pega}

\begin{tabular}{cccc}
\hline \multicolumn{2}{c}{ CM - Tempo de pega } & \multicolumn{2}{c}{ CG - Tempo de pega } \\
\hline Tempo (minutos) & Leitura $(\mathrm{mm})$ & Tempo (minutos) & Leitura $(\mathrm{mm})$ \\
\hline 30 & 0 & 30 & 0 \\
30 & 0 & 30 & 0 \\
30 & 0 & 30 & 0 \\
30 & 0 & 30 & 0 \\
30 & 0 & 30 & 2 \\
30 & 0 & 15 & 4 \\
15 & 1 & 15 & 7 \\
15 & 16,5 & 15 & 15 \\
15 & 19 & 15 & 16 \\
15 & 34 & 15 & 24 \\
15 & 50 & 15 & 26 \\
& & 15 & 29 \\
& & 15 & 30 \\
& & 15 & 45
\end{tabular}

Do ensaio de resistência foram obtidos os resultados mostrados na Tabela 2 com os corpos de prova de cimento $(\mathrm{CM})$, não havendo discrepância entre os corpos de prova. Com idade de 3 dias, obteve-se uma média de tensão de 10,3 MPa. De 7 dias, uma média de 23,7 MPa e com 28 dias, uma média de 32,8 MPa.

Tabela 2 - Resultados do ensaio de resistência à compressão

\begin{tabular}{cccccc}
\hline Identificação & Idade (dias) & CP & Carga (N) & Tensão (MPa) & Média (MPa) \\
\hline \multirow{2}{*}{ CM } & \multirow{2}{*}{3} & 1 & 12100 & 6,2 & 10,3 \\
& & 2 & 24400 & 12,4 & \\
& 3 & 16100 & 8,2 & 23,7 \\
CM & \multirow{3}{*}{7} & 5 & 28400 & 14,5 & 32,8 \\
& & 6 & 45200 & 23,0 & 23,1 \\
\end{tabular}


Do ensaio de resistência com os corpos de prova substituindo agregado por resíduos de girassol, foram obtidos os resultados mostrados na Tabela 3. Observou-se que há um aumento significativo quanto à resistência conforme o tempo de cura aumenta. Não havendo discrepância entre os corpos de prova.

Tabela 3 - Resultados do ensaio de resistência à compressão

\begin{tabular}{cccccc}
\hline Identificação & Idade (dias) & CP & Carga (N) & Tensão (MPa) & Média (MPa) \\
\multirow{2}{*}{ CG } & \multirow{2}{*}{3} & 2 & 900 & 0,5 & 0,4 \\
& & 3 & 700 & 0,5 & 0,4 \\
& 4 & 900 & 0,5 & 0,6 \\
CG & \multirow{2}{*}{7} & 5 & 1100 & 0,6 & 1,1 \\
& & 6 & 1500 & 0,8 & 0,5 \\
\end{tabular}

Os resultados de resistência apresentaram uma redução $96 \%$ se comparados os corpos de prova CG com CM. O CG, com idade de 3 dias, possui uma média de 0,4 MPa; com 7 dias, uma média de 0,6 MPa e com 28 dias, uma média de 1,1 MPa.

\section{CONCLUSÃO}

É possível concluir que os ensaios para avaliação do potencial de substituição do agregado por resíduos de girassol são úteis para futuros trabalhos. Uma alternativa vista é a utilização deste resíduo após a passagem pela etapa de calcinação, que consiste na colocação dos resíduos dentro da estufa por 6 horas a $300^{\circ} \mathrm{C}$. Este procedimento é realizado para transformá-los em cinzas, devido a sua quantidade de sílica.

Contudo, ainda é possível notar que o resíduo é constituído principalmente por partículas de $2 \mathrm{~mm}$, conforme a curva granulométrica, observando-se que não necessita passar por mais processos para diminuição de sua granulometria.

Quanto à resistência à compressão concluiu-se que aumenta com o passar do tempo tanto em CM como em CG. Porém, somente os corpos de prova CM alcançaram os índices especificados pela norma para a média mínima de tensão, que é de $30 \mathrm{MPa}$. 
Constatou-se que a finura do cimento é grande influenciadora na velocidade de endurecimento e reatividade, o referente ensaio obteve índices menores de $10 \%$, como a norma permite.

Já na determinação do tempo de pega, dentro dos parâmetros da NBR 5736 de ensaio, tanto CM quanto CG ficaram de acordo com o especificado da embalagem, no qual o tempo de início de pega é maior que $1 \mathrm{~h}$, e o tempo de fim de pega é menor que $12 \mathrm{~h}$.

\section{REFERÊNCIAS}

ASSOCIAÇÃO BRASILEIRA DE NORMAS TÉCNICAS. NBR 11579: Cimento Portland: Determinação da finura por meio da peneira $75 \mathrm{~mm}$ ( $\left.n^{\circ} 200\right)$. Rio de Janeiro, 1991.

ASSOCIAÇÃO BRASILEIRA DE NORMAS TÉCNICAS. NBR 7215: Cimento Portland: Determinação da resistência à compressão. Rio de Janeiro, 1995.

ASSOCIAÇÃO BRASILEIRA DE NORMAS TÉCNICAS. NBR NM-ISO 2395: Peneira de Ensaio e Ensaio de Peneiramento. Rio de Janeiro, 1997.

ASSOCIAÇÃO BRASILEIRA DE NORMAS TÉCNICAS. NBR 5736: Cimento Portland Pozolânico. Rio de Janeiro, 1991.

CAMARINI, G.; PIMENTEL, L.L. Avaliação de compósitos de biomassa vegetal-cimento modificados por polímero. Revista Brasileira de Ciências Ambientais, n. 1, p. 26-33, 2005.

FILHO, R. D. T.; ENGLAND, G. L.; GHAVAMI, K. Comportamento em compressão de argamassas reforçadas com fibras naturais. Revista Brasileira de Engenharia Sanitária e Ambiental, v. I, p.79-88, 1997.

LISBOA, J. S.; BINI, M. P. M.; ANTUNES, M. L. P. Estudo da incorporação de resíduos da fabricação de pás eólicas para aerogeradores em Cimento Portland. $26^{\circ}$ CONGRESSO BRASILEIRO DE ENGENHARIA SANITÁRIA E AMBIENTAL. Anais... Porto Alegre, 2012.

MENDONÇA, S. F.; TENÓRIO, T. M.; MARQUES, S. K. J. Estudo da incorporação de cinzas do bagaço de cana- de-açúcar em formulações para fabricação de tijolos solo-cimento. VVII CONNEPI - CONGRESSO NORTE NORDESTE DE PESQUISA E INOVAÇÃO. Anais... Palmas, Tocantis, 2012.

MOTTA, C. J. A.; PESTANA, C. F. M. Co-produtos na produção de biodiesel. Revista Virtual de Química, v. 3, n. 5, p. 416-425, 2011.

TEIXEIRA, M. G. Aplicação de conceitos da ecologia industrial para a produção de materiais ecológicos: o resíduo de madeira. Dissertação (Mestrado Profissional em Gerenciamento de Tecnologias Ambientais no Processo Produtivo) - Universidade Federal da Bahia. Salvador, 2005 . 